Pediat. Res. 1: 277-286 (1967)

Acidosis

acidosis, metabolic

respiratory alkalosis hyperventilation

salicylism

hypercapnia

\title{
Changes in Intracellular Hydrogen Ion Activity in Acute Experimental Salicylate Intoxication
}

\author{
J.B. MooN ${ }^{[34]}$ and D. O'BRIEN \\ Department of Pediatrics, University of Colorado Medical Center, Denver, Colorado, USA
}

Extract

This study was devised to ascertain (1) the extent and direction of changes in intracellular hydrogen ion activity in unmodified salicylate intoxication, and (2) whether an intracellular metabolic acidosis was unmasked or decompensated when the $\mathrm{P}_{\mathrm{CO} 2}$ was maintained at normal levels. Sixteen mongrel dogs were studied in 3 groups: 1. Controls; 2 . Salicylate intoxicated dogs (given $300 \mathrm{mg} / \mathrm{kg}$ of sodium salicylate intravenously; and 3. Mechanically hyperventilated dogs given no salicylate. Skeletal muscle intracellular hydrogen ion activity was determined at intervals in each group using ${ }^{14} \mathrm{C}$ labelled 2,4-dimethyl oxazolidinedione, tritiated water and ${ }^{36} \mathrm{Cl}$ ion. In the controls the intracellular hydrogen ion activity did not deviate significantly from the average value of $130.9 \mathrm{nEq} / \mathrm{l}^{*}$ over periods ranging from 4-12 hours. In group 2, intracellular hydrogen ion activity fell from a presalicylate value of $129.7 \mathrm{nEq} / \mathrm{l}$ to 102.1 at 2 hours, 87.0 at 3 hours, and 81.5 at 4 hours. When $2-4 \% \mathrm{CO}_{2}$ was given and the $\mathrm{P}_{\mathrm{CO}_{2}}$ was stabilized at $30-40 \mathrm{~mm} \mathrm{Hg}$, the intracellular hydrogen ion activity returned to normal. In the group 3 dogs it fell from $136.8 \mathrm{nEq} / \mathrm{l}$ to 87.7 over 4 hours and also returned to normal when $\mathrm{CO}_{2}$ was given. Results from 3 representative dogs are shown in figure 2 . The authors conclude that (1) intracellular hydrogen ion activity falls significantly in salicylate intoxication due to salicylate-induced hyperventilation, and (2) no major metabolic acidosis could be demonstrated within the cells when the $\mathrm{P}_{\mathrm{CO} 2}$ was held at normal levels.

\section{Speculation}

The use of THAM or large doses of sodium bicarbonate to alkalinize urine may not be entirely benign though the usefulness of these drugs as salicyluric agents is not questioned. Inhalation of $\mathrm{CO}_{2}$ may warrant further research as a possible therapeutic agent for cases of salicylate intoxication in which a metabolic acidosis has not become apparent from extracellular fluid data.

$* n E q=10^{-9}$ equivalents.

\section{Introduction}

Acute salicylate intoxication is commonly associated with a primary respiratory alkalosis ${ }^{1}$ on which a metabolic acidosis frequently supervenes $[28,30]$. Depending somewhat upon age and the time elapsed since in- gestion, either process may predominate and the plasma hydrogen ion activity, $\left[\mathrm{H}^{+}\right]_{\mathrm{p}}$, may fall or rise accordingly [30]. A number of strong acids are produced in salicylism and lactate [11], pyruvate [11], $\beta$-hydroxybutyrate and acetoacetate [26] accrue in the body fluids. All of these are of intracellular origin. Intra- 
cellular hydrogen ion activity, $[\mathrm{H}+]_{i}$, might, therefore, be expected to rise were it not for the accompanying hyperventilation, which by lowering the intracellular $\mathrm{CO}_{2}$ tension tends to cause $[\mathrm{H}+]_{\mathrm{i}}$ to fall $[5,29]$. Thus, in salicylate intoxication, two processes may occur simultaneously, each acting to change $\left[\mathrm{H}^{+}\right]_{\mathrm{i}}$ in opposite directions.

Primarily on the basis of changes in the extracellular fluid, a number of therapeutic agents have been suggested $[11,13,14,21]$. Of these, sodium bicarbonate and tris-(hydroxymethyl)-aminomethane (THAM) are known to alkalinize intracellular fluid $[1,2,17,23$, 25] while acetazolamide and especially carbon dioxide acidify it $[1,2,17,18,25,29]$. This study was, therefore, devised to ascertain (1) the extent and direction of changes in $\left[\mathrm{H}^{+}\right]_{\mathrm{i}}$ in unmodified salicylate intoxication, and (2) whether an intracellular metabolic acidosis is unmasked or decompensated if the $\mathrm{P}_{\mathrm{CO}_{2}}$ is maintained at normal levels with carbon dioxide.

\section{Materials and Methods}

Sixteen adult male mongrel dogs weighing between 5.3 and $12.6 \mathrm{~kg}$ were assigned to the following study groups by double-bdind technique: group I, shamtreated controls; group II, salicylate intoxicated dogs with and without treatment with $\mathrm{CO}_{2}$ in percentages sufficient to normalize the $\mathrm{Pa}_{\mathrm{CO}_{2}}$; and group III, mechanically hyperventilated, $\mathrm{CO}_{2}$-treated dogs given no salicylate. All dogs were given the smallest dose of sodium pentobarbital required to effect general anesthesia. An endotracheal tube was then inserted, but the animals were allowed to breathe spontaneously. Immediately following induction, each received intravenously $20 \mu \mathrm{c} / \mathrm{kg}$ of tritiated water, $2.0 \mu \mathrm{c} / \mathrm{kg} 5,5^{\prime}$ dimethyloxazolidine-2,4-dione-2 ${ }^{14}-\mathrm{C}(\mathrm{DMO})^{2}$ and 1.0 $\mu \mathrm{c} / \mathrm{kg}$ of NaCl-${ }^{36} \mathrm{Cl}$. The right femoral artery and left jugular vein were cannulated. Clotting in the former was prevented by a heparin lock and in the latter by a slow saline infusion. A thermometer was inserted $8 \mathrm{~cm}$ into the rectum. Two and one half to three hours were allowed for the isotope concentrations to achieve steady states following which baseline samples were taken. All blood samples were from the artery; all injections were intravenous. Blood removed in sampling was promptly replaced with equal volumes of isotonic saline. Skeletal muscle biopsies were performed rapidly from muscles of the extremities excepting the right hind limb (due to the presence of the arterial cannula).

1 Acid-base terminology used in this report is in accordance with recent recommendations [31].

2 New England Nuclear Corporation, Boston, Massachusetts.
Muscle samples of $650 \mathrm{mg}$, trimmed of visible fat and connective tissue, were immediately placed in 10.0 $\mathrm{ml}$ N.C.S. ${ }^{\circledR}$ Solubilizer ${ }^{3}$, minced with scissors, and gently agitated for 48-72 hours. Samples of heparinized plasma of $2.0 \mathrm{ml}$ were placed without delay in $7.0 \mathrm{ml}$ of N.C.S. ${ }^{\circledR}$. Whole blood $\mathrm{pH}$ was determined with a Radiometer 4C, null point, $\mathrm{pH}$ meter using a Radiometer G297/G2 glass electrode at $38.0^{\circ}$. Plasma $\mathrm{CO}_{2}$ content was determined with a Kopp-Natelson microgasometer [20]. $\mathrm{Pa}_{\mathrm{CO}_{2}}$ and plasma concentrations of $\mathrm{HCO}_{3}^{-}$were calculated from the Henderson-Hasselbach equation after the $\mathrm{pH}, \mathrm{pK}^{\prime}$ and $\alpha$ (the solubility factor for $\mathrm{CO}_{2}$ ) had been corrected for deviations in body temperature. The equations used for temperature correction were $: \mathrm{pH}$ (temperature corrected) $=\mathrm{pH}$ (measured) $-0.0146 \Delta \mathrm{T}, \mathrm{pK}^{\prime}=6.10-0.005 \Delta \mathrm{T}$, and $\alpha=0.0301-$ $0.0007 \Delta \mathrm{T}$, where $\Delta \mathrm{T}=$ rectal temperature- $38.0^{\circ}$ [19]. Values for $[\mathrm{H}+]_{\mathrm{p}}$ were then calculated by exponentiating the $-\mathrm{pH}$. Hemoglobin was determined as cyanmethemoglobin [20] and base excess was calculated from a Siggaard-Andersen nomogram [27]. Lactate and pyruvate were determined enzymatically with $\mathrm{L}(+)$ stereospecific lactic dehydrogenase [20]. In addition, total lactate was determined by the method of BARKER and Summerson [3] and salicylate by the fluorimetric method of SAx.TZMAN [24]. The presence of salicylate did not interfere with any of the above methods.

$\left[\mathrm{H}^{+}\right]_{\mathrm{i}}$ was calculated from intracellular $\mathrm{pH}$ as determined by SchlOERB and Grantham's modification [25] of the WADDELL-BUTLER technique [29] with some changes to be described. Briefly, the determination is based on the steady state distribution between plasma and intracellular water of the weak acid DMO. Assuming the uncharged form (HDMO) is at equal activity on both sides of the cell membrane this distribution is related to the hydrogen ion activity of the intracellular water, and from it, intracellular $\mathrm{pH}$ and hence $\left[\mathrm{H}^{+}\right]_{i}$ can be calculated. The present method involved discrimination of tritiated water, $\mathrm{DMO}-{ }^{14} \mathrm{C}$ and ${ }^{36} \mathrm{Cl}$ ion in plasma and skeletal muscle by 3 -channel liquid scintillation spectrometry.

The following solutions are prepared:

1. Water background solution (WB): $2.5 \mathrm{ml}$ of distilled water plus $12.5 \mathrm{ml}$ N.C.S. ${ }^{\circledR}$.

2. Muscle background solution (MB): $650 \mathrm{ml}$ of nonradioactive fresh dog skeletal muscle finely minced in $10.0 \mathrm{ml}$ of N.C.S. ${ }^{\circledR}$ and agitated for $48-72$ hours.

3. Plasma background solution (PB): $2.0 \mathrm{ml}$ of nonradioactive dog plasma added to $7.0 \mathrm{ml}$ of N.C.S. ${ }^{\circledR}$.

4. Scintillation fluid-toluene (reagent grade), 600 $\mathrm{ml}$; methylcellosolve (reagent grade, essentially free of peroxides), $400 \mathrm{ml}$; naphthalene (reagent grade)

${ }^{3}$ Nuclear Chicago Corporation, Des Plaines, Illinois 
Changes in intracellular hydrogen ion activity in acute experimental salicylate intoxication 279

Table $I$. Contents of scintillation vials (values in $\mathrm{ml}$ )

\begin{tabular}{|c|c|c|c|c|c|c|c|c|c|c|c|}
\hline 总 & 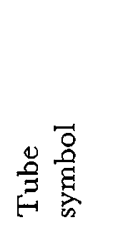 & 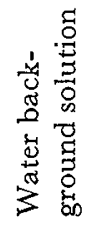 & 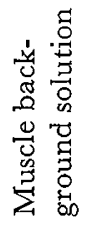 & 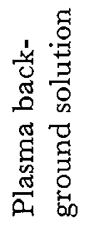 & 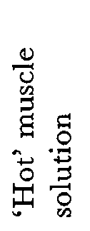 & 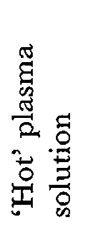 & 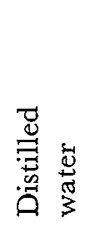 & 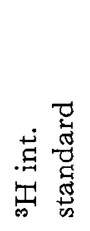 & 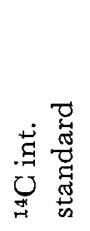 & 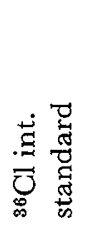 & 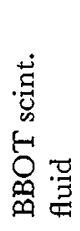 \\
\hline $1-4$ & WB & 2.0 & & & & & 0.2 & & & & 15.0 \\
\hline $5-8$ & $\mathrm{MB}$ & & 2.0 & & & & 0.2 & & & & 15.0 \\
\hline $9-12$ & $\mathrm{~PB}$ & & & 2.0 & & & 0.2 & & & & 15.0 \\
\hline 13 & ${ }^{3} \mathrm{H}-\mathrm{IS}$ & 2.0 & & & & & & 0.2 & & & 15.0 \\
\hline 14 & ${ }^{14} \mathrm{C}-\mathrm{IS}$ & 2.0 & & & & & & & 0.2 & & 15.0 \\
\hline 15 & ${ }^{36} \mathrm{Cl}-\mathrm{IS}$ & 2.0 & & & & & & & & 0.2 & 15.0 \\
\hline 16 & M1 & & & & 2.0 & & 0.2 & & & & 15.0 \\
\hline 17 & M2 & & & & 2.0 & & & 0.2 & & & 15.0 \\
\hline 18 & M3 & & & & 2.0 & & & & 0.2 & & 15.0 \\
\hline 19 & M4 & & & & 2.0 & & & & & 0.2 & 15.0 \\
\hline 20 & $\mathrm{P} 1$ & & & & & 2.0 & 0.2 & & & & 15.0 \\
\hline 21 & $\mathrm{P} 2$ & & & & & 2.0 & & 0.2 & & & 15.0 \\
\hline 22 & P3 & & & & & 2.0 & & & 0.2 & & 15.0 \\
\hline 23 & $\mathrm{P} 4$ & & & & & 2.0 & & & & 0.2 & 15.0 \\
\hline
\end{tabular}

$80 \mathrm{~g} ; 2$ 2,5-bis-[2-(5-tert-butyl-benzoxazolyl)]-thiopene (B.B.O.T. $)^{4}, 4.0 \mathrm{~g}$.

5. Aqueous internal standard solutions $\left({ }^{3} \mathrm{H}-\mathrm{IS}\right.$, ${ }^{14} \mathrm{G}-\mathrm{IS}$ and $\left.{ }^{36} \mathrm{Cl}-\mathrm{IS}\right)$ : Aqueous solutions of ${ }^{3} \mathrm{H},{ }^{14} \mathrm{C}$ and ${ }^{36} \mathrm{Cl}$ prepared with $0.2 \mathrm{ml}$ of each, providing $50-60 \times$ $10^{3}$ counts per minute in each channel of a 3-channel liquid scintillation spectrometer when operating at the optimal gain setting for its respective isotope.

Scintillation vials of $15 \mathrm{ml}$ volume were filled as specified in table $\mathrm{I}$, bearing in mind that when internal standards are added, accurate repetitive delivery technique is critical [25].

The vials were placed in a Packard Tri-Carb ${ }^{4}, 3-$ channel, liquid scintillation spectrometer and after 2 hours of dark and cold adaptation, triplicate 10 minute counts were obtained on each vial and averaged. An IBM 7044 digital computer was used to perform all calculations.

Experimental Grouping of the Dogs

Group I: Contrals. Dogs 3, 10,16 and 17 were sham controls not treated with salicylate, $\mathrm{CO}_{2}$ or positive pressure hyperventilation.

Group II a: Unmodified salicylate intoxicated dogs. Dogs 4, 5, 8, 9 and 12-15 underwent baseline sampling, received $300 \mathrm{mg} / \mathrm{kg}$ of sodium salicylate intravenously over a period of two minutes and followed for four or more hours with serial determinations.

${ }^{4}$ Packard Instrument Company, Downer's Drove, Ill.
Group IIb: Salicylate intoxicated $\mathrm{CO}_{2}$-treated dogs. After four hours in group II a, dogs 12-15 were given 2, 3 or $4 \% \mathrm{CO}_{2}$ in air through a Rudolph valve to prevent rebreathing. The $\mathrm{CO}_{2}$ percentage was selected which most nearly corrected the blood $\mathrm{pH}$ to baseline levels. After 2 hours of $\mathrm{CO}_{2}$ treatment, dogs 14 and 15 were returned to room air for two hours and restudied. Following this, $\mathrm{CO}_{2}$ was readministered.

Group III: Hyperventilated $\mathrm{CO}_{2}$-treated dogs. After baseline sampling and sham injections of isotonic saline, dogs 18-20 were artificially hyperventilated with compressed air in a stepwise fashion to simulate the initial stage of salicylism. At the end of four hours, compressed air with 2,3 or $4 \% \mathrm{CO}_{2}$ was used to ventilate the dogs, maintaining hyperventilation, but correcting hypocapnia.

\section{Results}

Group I: Controls. Four dogs were studied for periods ranging from four to twelve hours following the baseline studies. Intracellular hydrogen ion activities, $\left[\mathrm{H}^{+}\right]_{\mathrm{i}}$, are plotted against time in figure 1 . The mean $\left[\mathrm{H}^{+}\right]_{\mathrm{i}}$ for all control values was $130.9 \pm 8.7(\mathrm{SD}) \mathrm{nEq} / 1$ of nonchloride space, muscle water. It may be noted that no significant changes in $\left[\mathrm{H}^{+}\right]_{\mathrm{i}}$ occurred within the periods of time studied.

Group IIa: Unmodified salicylate intoxication. After allowing two and one-half to three hours for the achievement 
of an isotopic steadystate, baseline sampling was performed. The mean baseline $\left[\mathrm{H}^{+}\right]_{i}$ was $129.7 \pm 15.8$ (SD) $\mathrm{nEq} / \mathrm{l}$. This value cannot be statistically distinguished from that of the controls ( $\mathrm{p}>0.3$ by t test). $1.0 \mathrm{mI} / \mathrm{kg}$ of a $300 \mathrm{mg} / \mathrm{ml}$ aqueous sodium salicylate solution was then slowly injected into the venous catheter. Within 20 seconds of injection all dogs developed obvious hyperpnea. This subsided briefly only to recur within 30-60 minutes and progress in depth over the next several hours. Within two hours of salicylate administration, respiratory alkalosis with alkalemia was apparent. The mean two hour $\left[\mathrm{H}^{+}\right]_{\mathrm{i}}$ had fallen to $102.1 \pm 15.0$ (SD) $\mathrm{nEq} / \mathrm{l}$. By 3 hours the mean $\left(\mathrm{H}^{+}\right)_{\mathrm{i}}$ had fallen to $87.0 \pm$ 4.72 (SD) $n E q / 1$ and by 4 hours to $81.5 \pm 10.7$ (SD) $\mathrm{nEq} / \mathrm{l}$. These changes are all highly significant $(\mathrm{p}<0.01$

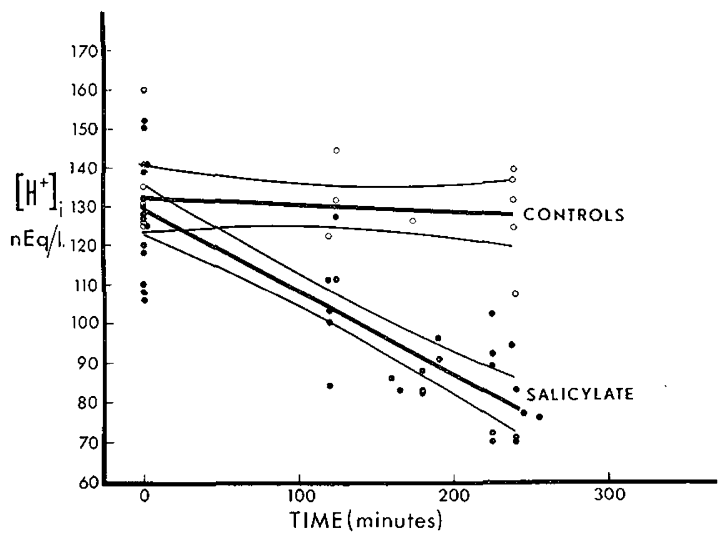

Fig. 1. Comparison of intracellular hydrogen ion activities in skeletal muscle of dogs with and without salicylate intoxication. (The linear least squares regression lines [dark] are bounded by curved lines defining the area which will include the regression lines $95 \%$ of the time. Circles represent control group data; dots represent data from the salicylate group.)

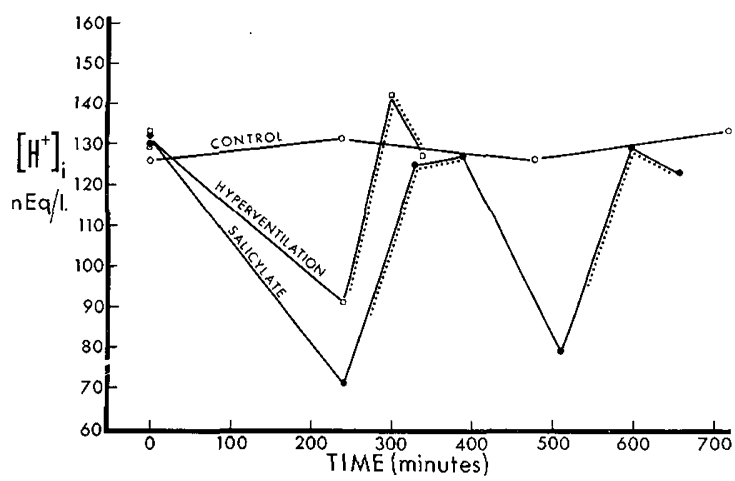

Fig. 2. Comparison of changes in in tracellular hydrogen ion activities in three representative dogs. (Consecutive dotting indicates the periods during which $\mathrm{CO}_{2}$ was administered.) by $t$ test). The data are plotted with their regression in figure 1. All corollary data are listed in table II.

Group IIb: Salicylate intoxicated $\mathrm{CO}_{2}$-treated dogs. Dogs 12-15, whose data from the first four hours following salicylate are included in group II $\mathrm{a}$, were then allowed to breathe spontaneously 2,3 or $4 \% \mathrm{CO}_{2}$ in air through a oneway Rudolph valve. No obvious increases in rate or depth of respirations were noted. The concentration of $\mathrm{CO}_{2}$ was selected which most nearly restored the blood $\mathrm{pH}$ to normal. As no significant changes occurred in buffer base concentration, this amounted to correcting the $\mathrm{Pa}_{\mathrm{CO}_{2}}$ to normal. The effect of the $\mathrm{CO}_{2}$ on $\left[\mathrm{H}^{+}\right]_{\mathrm{i}}$ was striking. The mean $\left[\mathrm{H}^{+}\right]_{\mathrm{i}}$ abruptly returned to, but not above, baseline levels $(\mathrm{p}>0.25)$.

After dog 14 had received $\mathrm{CO}_{2}$ for 170 minutes and $\operatorname{dog} 15$ had received $\mathrm{CO}_{2}$ for 120 minutes, the $\mathrm{CO}_{2}$ was discontinued. In two hours, a striking fall in $\left[\mathrm{H}^{+}\right]_{\mathrm{i}}$ had again occurred. Both dogs achieved levels of $\left[\mathrm{H}^{+}\right]_{i}$ of $79 \mathrm{nEq} / \mathrm{l}$. When they were again given $\mathrm{CO}_{2}$ in percentages sufficient to normalize the blood $\mathrm{pH},[\mathrm{H}+]_{\mathrm{i}}$ was again corrected to, but not above, the base line range.

Group III: Hyperventilated, $\mathrm{CO}_{2}$-treated dogs. Dogs 18-20 were allowed the usual two and one-half to three hours to achieve isotopic steady states and baseline samples were taken. The mean baseline $[\mathrm{H}+]_{i}$ was 136.8土6.5 (SD) $\mathrm{nEq} / \mathrm{l}$ which statistically cannot be distinguished from that of group II (presalicylate) ( $p>0.1$ ). Next, the dogs were given sham injections of isotonic saline and were hyperventilated with air in an incremental fashion over four hours using a positive pressure respirator. This was done to simulate the respiratory alkalosis seen in the salicylate-intoxicated dogs. Samples taken at four hours revealed that $[\mathrm{H}+]_{\mathrm{i}}$ had fallen 42,46 and $40 \mathrm{nEq} / \mathrm{l}$ respectively below the baseline. The numbers involved are too small to permit accurate statistical comparison, but are of the same order of magnitude and in the same direction as was seen in group II. Hyperventilation was then continued, but 2, 3 and $4 \% \mathrm{CO}_{2}$ in compressed air was substituted. As in the group II dogs, $[\mathrm{H}+]_{\mathrm{i}}$ was normalized; the mean $[\mathrm{H}+]_{i}$ after $\mathrm{CO}_{2}$ was $139.2 \pm 10.5(\mathrm{SD}) \mathrm{nEq} / \mathrm{l}$. This value is not significantly different from the baseline $(0.30<p<0.40)$.

Data from dogs 15, 17 and 20 are representative of the three groups and are plotted together in figure 2.

\section{Discussion}

The primary purpose of these studies was to resolve the opposing effects on $[\mathrm{H}+]_{i}$ of salicylate-induced respiratory alkalosis and metabolic acidosis. The salicylate-intoxicated animals all showed a fall in $\left[\mathrm{H}^{+}\right]_{\mathbf{i}}$ reflecting their hypocapnia, but this finding did not 
Changes in intracellular hydrogen ion activity in acute experimental salicylate intoxication 281

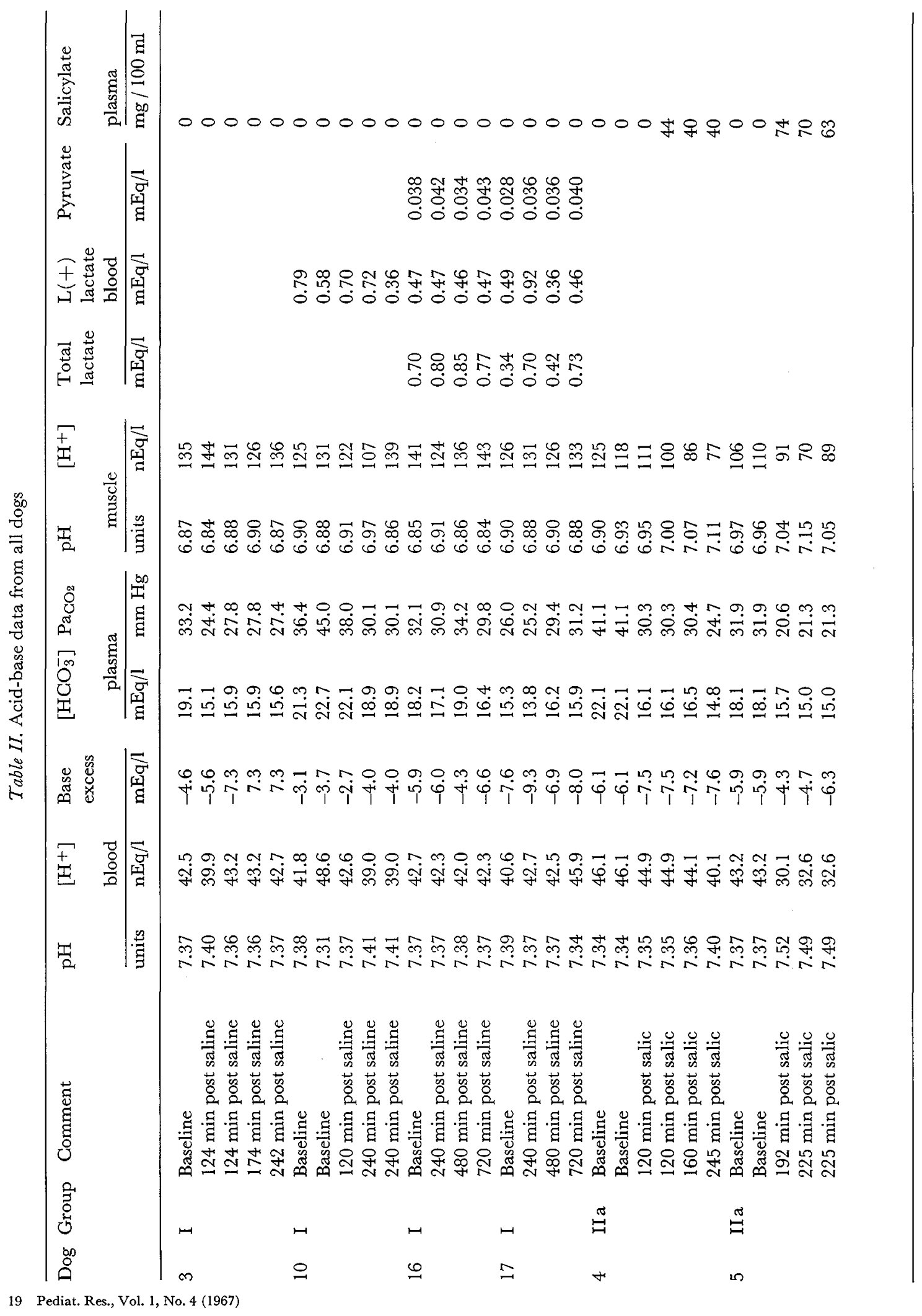




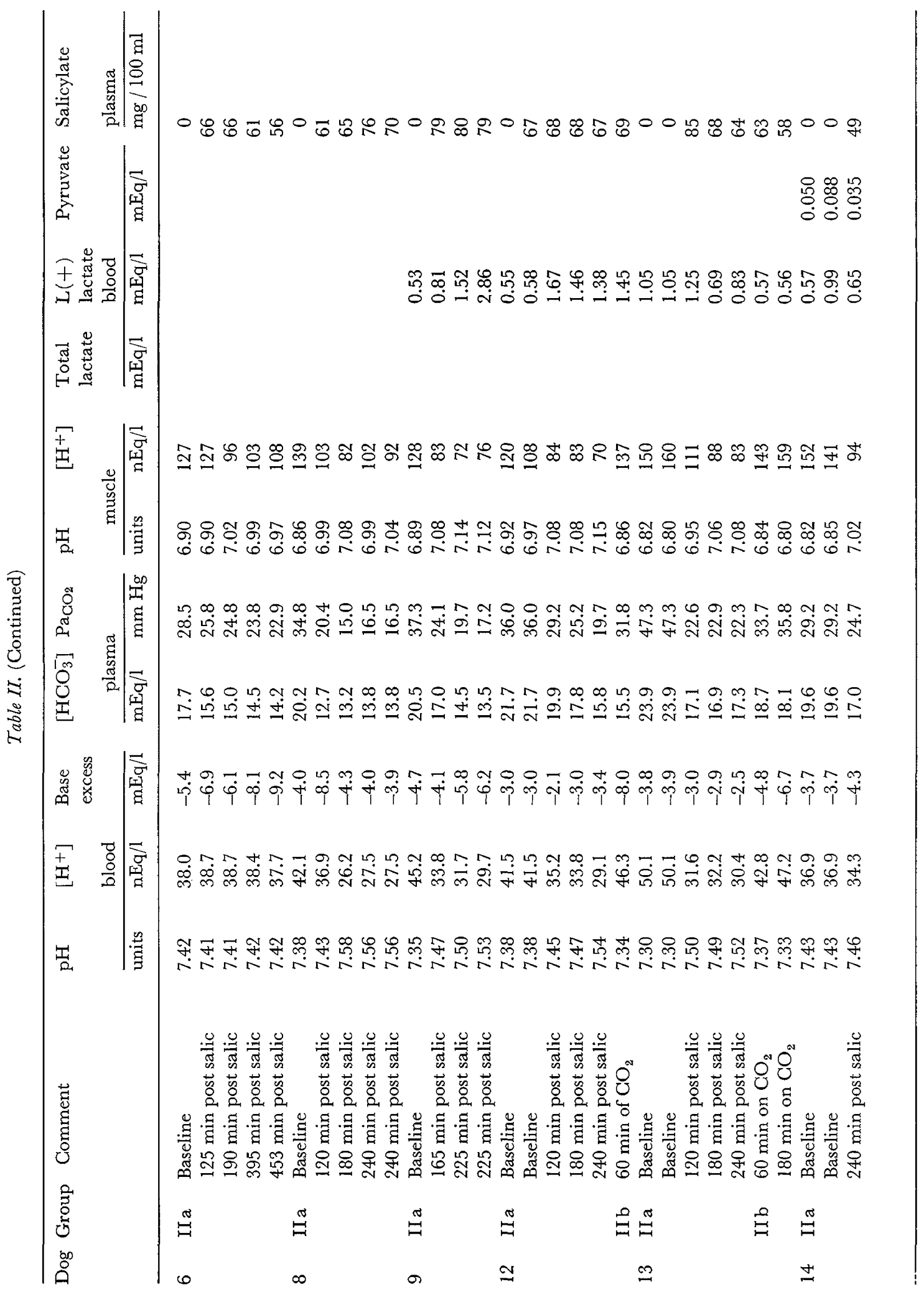


Changes in intracellular hydrogen ion activity in acute experimental salicylate intoxication 283

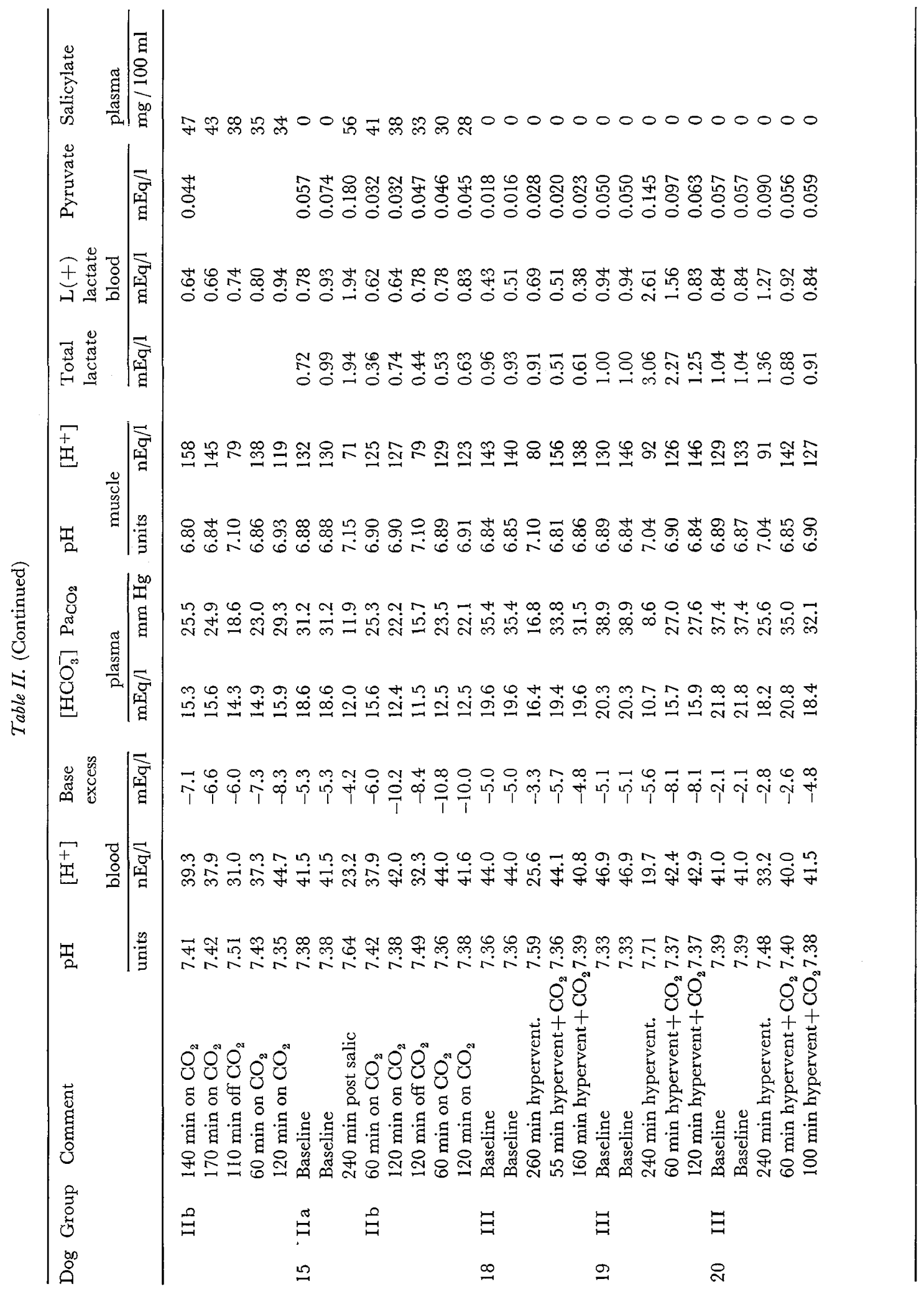


preclude a coexisting intracellular metabolic acidosis. There are, however, two points which suggest that an abnormal intracellular process tending to raise $\left[\mathrm{H}^{+}\right]_{\mathrm{i}}$ was not an important component. (1) When $\mathrm{CO}_{2}$ was administered to the intoxicated dogs $\left[\mathrm{H}^{+}\right]_{i}$ returned to, but not above, normal levels. This may indicate that either no significant intracellular metabolic acidosis existed, or it existed but was caused by hypocapnia rather than salicylates and had, therefore, been effectively treated by the time the muscle samples had been taken. Furthermore, if a significant intracellular metabolic acidosis had existed which was caused by metabolic effects of salicylate per se and not simply by hypocapnia, the $\left[\mathrm{H}^{+}\right]_{i}$ values from the salicylateintoxicated dogs should have been higher than those observed in the hyperventilated dogs receiving no salicylate. In fact, they were not, thus supporting the theory [11] that metabolic acidosis in salicylism is due to a respiratory effect rather than a direct effect of the drug on intermediary metabolism. (2) Evidence exists that hypocapnia causes increased production of lactic acid $[9,10,11,15]$ but the rises observed here were inconsequential when compared with those reported by others [11]. This fact evoked a careful reexamination of the method used in the determination of lactate in blood. Inasmuch as the enzymatic procedure was stereospecific and measured only $L(+)$ lactate [20], the possibility still existed that a $\mathrm{D}(-)$ lactic acidosis had been observed by other workers [11]. Therefore, the method of BARKER and SUMmerson [3] was employed which measures both the $\mathrm{L}(+)$ and $\mathrm{D}(-)$ epimers. Little difference was noted. When lactate rose in response to hypocapnia, it did so as $\mathrm{L}(+)$ lactate. When isocapnia was restored, blood lactate concentrations promptly returned to normal. Posner and Plum [22] have studied changes in lactate concentrations of both blood and cerebrospinal fluid and concluded that lactic acid production was ineffectual as a compensatory mechanism to oppose hypocapnia caused by either passive or salicylate-induced hyperventilation. Evidently the same holds true for intracellular fluid.

In summary, while metabolic acidosis and respiratory alkalosis both characterize salicylism in the experimental animal [11], the latter would appear to be the more significant. In salicylism in children the blood $\mathrm{pH}$ also tends to be inappropriately high for the degree of hypobasemia $[28,30]$. In two large series of unselected pediatric patients $[21,30]$, normal or elevated blood $\mathrm{pH}$ was the rule, acidemia the exception, despite the fact that metabolic acidosis was frequently observed. The absence of profound acidemia (low plasma $\mathrm{pH}$, high $\left[\mathrm{H}^{+}\right]_{\mathrm{p}}$ ) is not, therefore, a serious criticism of this study.

Of course, the reliability of these findings is still dependent on certain technical features of the experiments. To begin with, all measurements of $\left[\mathrm{H}^{+}\right]_{i}$ were performed on skeletal muscle. The reasons for selecting this tissue are as follows: (1) Skeletal muscle is substantial in bulk and capable of providing large quantities of strong, nonvolatile acids [29]; (2) It is richly endowed with mitochondria and contains all the important biochemical pathways known to be affected in salicylate intoxications; (3) Its extracellular fluid volume can be assessed as its chloride 'space' with accuracy sufficient for the DMO method [29]. Accurate methods of determining the e tracellular compartment of brain, liver or kidney have not been as firmly established. Regional differences in $\left[\mathrm{H}^{+}\right]_{\mathrm{i}}$ cannot, of course, be excleded by the present data.

The determination of $\left[\mathrm{H}^{+}\right]_{i}$ from the distribution of DMO between intra- and extracellular fluid is controversial and has been subjected to critical review on several occasions $[1,4,6,7,8,16,18,25,29]$. The normal values obtained in this study agree favorably with those of other studies based on the same principles [1, 5, 25, 29]. Recent work with intracellular glass microelectrodes has suggested that $\left[\mathrm{H}^{+}\right]_{\mathrm{i}}$ is normally closer to $850-1000 \mathrm{nEq} / \mathrm{l}$, a range substantially higher than that found in the present study, 131.4 \pm $11.9(\mathrm{SD}) \mathrm{nEq} / \mathrm{I}(\mathrm{N}=39)$. While little agreement exists on the normal range of $\left[\mathrm{H}^{+}\right]_{i}$, directional changes in $\left[\mathrm{H}^{+}\right]_{\mathrm{i}}$ appear to be similarly detected regardless of the method used. Unless salicylate somehow affects intracellular binding of DMO in a fashion which is reversed by $\mathrm{CO}_{2}$, then the probability exists that $\left[\mathrm{H}^{+}\right]_{\mathrm{i}}$ falls in salicylate intoxication. Until the above controversy is resolved, the absolute values for $\left[\mathrm{H}^{+}\right]_{i}$, but not the conclusions, remain in question.

This demonstration that salicylate-induced hypocapnia causes significant falls in $\left[\mathrm{H}^{+}\right]_{\mathrm{i}}$ may have certain therapeutic implications. Attempts are often made to alkalinize urine with substantial amounts of $\mathrm{NaHCO}_{3}$. Ordinarily $\mathrm{HCO}_{3}^{-}$causes a minimal fall in $\left[\mathrm{H}^{+}\right]_{\mathrm{i}}[12,29]$ which may be fortunate in view of the present findings. Tris-(hydroxymethyl)-aminomethane, on the other hand, buffers carbonic acid and readily alkalinizes intracellular fluid [23]. Vigorous attempts to alkalinize urine, especially in alkalemic patients, would seem ill-advised in view of this study. Whereas $\mathrm{CO}_{2}$ effectively normalized the acid-base characteristics of both blood and intracellular fluid, no account has been taken of its effects, if any, on salicylate excretion. Clinical use of $\mathrm{CO}_{2}$ cannot be advocated on the basis of these studies alone.

\section{Summary}

1. Intracellular hydrogen ion activity was determined in dog skeletal muscle with the 5,5'-dimethyl-2,4,-oxazolidinedione technique before and after the administration of toxic doses of sodium salicylate. 
Changes in intracellular hydrogen ion activity in acute experimental salicylate intoxication 285

2. A striking fall in intracellular hydrogen ion activity due to hyperventilation was uniformly observed in unmodified salicylate intoxication.

3. The administration of sufficient percentages of carbon dioxide to restore isocapnia corrected intracellular hydrogen ion activity to, but not above, the normal range and failed to unmask any intracellular metabolic acidosis.

4. Implications of these findings are discussed.

\section{References and Notes}

1. Adler, S.; Roy, A. and Relman, A. S. : Intracellular acid-base regulation. I. The response of muscle cells to changes in $\mathrm{CO}_{2}$ tension or extracellular bicarbonate concentration. J. clin. Invest. 44: 8 (1965).

2. Adler, S.; Rox, A. and Relman, A.S.: Intracellular acid-base regulation. II. The interaction between $\mathrm{CO}_{2}$ tension and extracellular bicarbonate in the determination of muscle cell $\mathrm{pH}$. J.clin. Invest. 44: 21 (1965).

3. Barker, S. B. and Summerson, W.H.: The colorimetric determination of lactic acid in biological material. J. biol. Chem. 138: 535 (1941).

4. Butler, T. C.: Active transport of 5,5-dimethyl2,4-oxazolidinedione. Science 151: 1564 (1966).

5. Galdwell, P.C.: Intracellular pH. Int. Rev. Cytol. 5: 229 (1956).

6. Campion, D.S.; Carter, N.W.; Rector, F.C., Jr. and SELDin, D.W. : Intracellular distribution of ${ }^{14}$ C-DMO. Clin. Res. 15: 76 (1967).

7. Dietschy, J.M. and Carter, N.W.: Active transport of 5,5-dimethyl-2,4-oxazolidinedione. Science 150: 1294 (1965).

8. Dietschy, J.M. and Carter, N.W.: Active transport of 5,5-dimethyl-2,4,-oxazolidinedione. Science 152: 799 (1966).

9. Dossetor, J. B.; Zвorowski, D.; Dixon, H. B. and PARe, J.A.P.: Hyperlactatemia due to hyperventilation: Use of $\mathrm{CO}_{2}$ inhalation. Ann. N.Y.Acad. Sci. 119: 1153 (1965).

10. Eichenholtz, A.; Mulhausen, R. O.; Anderson, W.E. and MACDonald, F.M.: Primary hypocapnia: a cause of metabolic acidosis. J.appl. Physiol. 17: 283 (1962).

11. Eichenholtz, A.; Mulhausen, R.O. and RedLEAF, P.S.: The nature of acid-base disturbance in salicylate intoxication. Metabolism 12: 164 (1963).

12. Elsmore, T. and Withrow, G.D.: Intracellular pH regulation in smooth and skeletal muscle. Fed. Proc. Amer. Soc. exp. Biol. 25: 289 (1966).

13. Feuerstein, R.C.; Finberg, L. and Fleishman, E.: The use of acetozoleamide in the therapy of salicylate poisoning. Pediatrics 25: 215 (1960).
14. Gemmind, W.D.; Sechrist, G.L.; Oliver, T.K., Jr., and Wheeler, W.E.: Use of Tris buffer to alkalinize the urine of young children with severe salicylism. J.Pediat. 63: 732 (1963).

15. Huckabee, W.E.: Relationships of pyruvate and lactate during anaerobic metabolism. I. Effects of infusion of pyruvate or glucose and of hyperventilation. J. clin. Invest. 37: 244 (1958).

16. Irvine, R.O.H.; Saunders, S.J.; Milne, M.D. and CRAWFORD, M.A.: Gradients of potassium and hydrogen ion in potassium-deficient voluntary muscle. Clin. Sci. 20: 1 (1960).

17. Kostyuk, P.G. and Sorokina, Z.A.: On the mechanism of hydrogen ion distribution between cell protoplasm and the medium; in: Membrane transport and metabolism. Proceedings of a symposium held in Prague (ed. Kleinzeller, A. and Kotyk, A.), p. 131 (Academic Press, New York 1961).

18. Miller, R.B.; Tyson, I. and Relman, A.S.: pH of isolated resting skeletal muscle and its relation to potassium content. Amer. J. Physiol. 204: 1048 (1963).

19. National Research Council: Handbook of respiration, p. 86 (Saunders, Philadelphia 1958).

20. O'Brien, D. ; Ibbott, F.A. and Rodgerson, D. O.: Laboratory manual of pediatric microbiochemical techniques, 4th ed. (Harper and Row, New York 1967) (in press).

21. Oliver, T.K. and Dyer, M.E.: The prompt treatment of salicylism with sodium bicarbonate. Amer. J. Dis. Child. 99: 553 (1960).

22. Posner, J.B. and Plum, F.: Failure of hyperventilation to produce acidosis. Fed. Proc. Amer. Soc. exp. Biol. 25: 264 (1966).

23. Robin, E.D.; Wilson, R.J. and BromberG, P.A.: Intracellular acid-base relations and intracellular buffers. Ann. N.Y.Acad. Sci. 92: 539 (1961).

24. Saltzman, A.: Fluorophotometric method for the estimation of salicylate in blood. J. biol. Chem. 174: 399 (1948).

25. Schloerb, P.R. and Grantham, J.: Intracellular $\mathrm{pH}$ measurement with tritiated water, carbon-14 labeled 5,5-dimethyl-2,4-oxazolidinedione, and chloride-36. J. Lab. clin. Med. 65: 669 (1965).

26. SchWARTz, R. and LANDY, G.: Organic acid excretion in salicylate intoxication. J. Pediat. 66: 658 (1965).

27. SiggaARd-Andersen, O.: Blood acid-base alignment nomogram. Scales for $\mathrm{pH}, \mathrm{pCO}_{2}$, base excess of whole blood of different hemoglobin concentrations, plasma bicarbonate, and plasma total $\mathrm{CO}_{2}$. Scand.J. clin. Lab. Invest. 15: 211 (1963).

28. Singer, R.B.: The acid-base disturbance in salicylate intoxication. Medicine (Baltimore) 33: 1 (1954). 
29. WAdDELL, W.J. and Butler, T. G. : Calculation of intracellular $\mathrm{pH}$ from the distribution of 5,5-dimethyl-2,4-oxazolidinedione (DMO). Application to skeletal muscle of the dog. J. clin. Invest. 38: 720 (1959).

30. Winters, R.W.; White, J.S.; Hughes, M. C. and ORDWAY, N.K.: Disturbances of acid-base equilibrium in salicylate intoxication. Pediatrics 23: 260 (1959).
31. Winters, R.W.: Terminology of acid-base disorders. Ann. N.Y.Acad. Sci. 133: 211 (1966).

32. The authors wish to thank Dr. PAul R. Schloerb for invaluable assistance and guidance with the DMO method.

33. Supported by USPHS grants FR-69 and TIHD108.

34. Moon, J. B., M. D., Department of Pediatrics, University of Colorado Medical Center, Denver, Col. 80220 (USA). 